\title{
Occurrence of potentially pathogenic Vibrio in oysters (Crassostrea gigas) and waters from bivalve mollusk cultivations in the South Bay of Santa Catarina
}

\author{
Roberta Juliano Ramos ${ }^{[1]}$, Letícia Adélia Miotto $^{[1]}$, Marília Miotto ${ }^{[1]}$, Nelson Silveira Junior ${ }^{[2]}$, \\ Andréia Cirolini ${ }^{[1]}$, Helen Silvestre da Silva ${ }^{[1]}$, Dália dos Prazeres Rodrigues ${ }^{[3]}$ \\ and Cleide Rosana Werneck Vieira ${ }^{[1]}$
}

[1]. Laboratório de Microbiologia de Alimentos, Departamento de Ciência e Tecnologia de Alimentos, Universidade Federal de Santa Catarina, Florianópolis, SC [2]. Associação de Maricultores do Sul da Ilha, Florianópolis, SC. [3]. Laboratório de Enterobactérias, Instituto Oswaldo Cruz, Rio de Janeiro, RJ.

\begin{abstract}
Introduction: This research aimed to identify and quantify potentially pathogenic Vibrio from different cultivations of bivalve shellfish in the State of Santa Catarina, Brazil, and water regions in the South Bay, as well as correlate the incidence of these microorganisms with the physicochemical parameters of marine waters. Methods: Between October 2008 and March 2009, 60 oyster and seawater samples were collected from six regions of bivalve mollusk cultivation, and these samples were submitted for Vibrio counts. Results: Twenty-nine (48.3\%) oyster samples were revealed to be contaminated with one or more Vibrio species. The Vibrio parahaemolyticus and Vibrio vulnificus counts in the samples ranged from $<0.5 \log _{10}$ Most Probable Number (MPN) g $\mathrm{g}^{-1}$ to $2.3 \log _{10} \mathrm{MPN} \mathrm{g}^{-1}$ oyster and from $<0.5 \log _{10} \mathrm{MPN} \mathrm{g}^{-1}$ to $2.1 \log _{10} \mathrm{MPN} \mathrm{g}^{-1}$ oyster, respectively. Of the 60 seawater samples analyzed, $44(73.3 \%)$ showed signs of contamination with one or more vibrio species. The counts of V. parahaemolyticus and V. vulnificus in the samples ranged from $<0.3 \log _{10} \mathrm{MPN} \cdot 100 \mathrm{~mL}^{-1}$ to $1.7 \log _{10} \mathrm{MPN} \cdot 100 \mathrm{~mL}^{-1}$ seawater and from $<0.3 \log _{10}$ MPN $100 \mathrm{~mL}^{-1}$ to $2.0 \log _{10} \mathrm{MPN} \cdot 100 \mathrm{~mL}^{-1}$ seawater, respectively. A positive correlation between $V$. vulnificus counts and the seawater temperature as well as a negative correlation between the V. parahaemolyticus counts and salinity were observed. Conclusions: The results suggest the need to implement strategies to prevent vibrio diseases from being transmitted by the consumption of contaminated bivalve shellfish.
\end{abstract}

Keywords: Oyster. Crassostrea gigas. Vibrio parahaemolyticus. Vibrio vulnificus. Shellfish. Polymerase chain reaction.

\section{INTRODUCTION}

In Brazil, the production of bivalve shellfish occurs primarily in the Southern region of the State of Santa Catarina because of the excellent geographical conditions of this area for the cultivation of marine organisms, such as the presence of a large number of bays, which facilitates the establishment of marine farms ${ }^{1,2}$. In 2011, approximately 18.3 tons of shellfish were sold in the State of Santa Catarina, and the largest production of oysters (Crassostrea gigas) occurred at marine farms located in the South Bay near the Island of Santa Catarina.

In addition to indicators of fecal contamination, which are widely used to assess the microbiological quality of bivalve mollusks, different species of the Vibrio genus occur naturally

Address to: Dr ${ }^{\mathrm{a}}$ - Roberta Juliano Ramos. Lab. de Microbiologia de Alimentos/ Dept $^{\underline{o}}$ de Ciência e Tecnologia de Alimentos/UFSC. Rod. Admar Gonzaga 1346, 88034-001 Florianópolis, SC, Brasil.

Phone: 5548 3721-5379; Fax: 5548 3721-9943

e-mail: robertajulianoramos@yahoo.com.br

Received 24 March 2014

Accepted 23 June 2014 in marine, coastal and estuary environments. However, some species, such as Vibrio parahaemolyticus, Vibrio vulnificus and Vibrio cholerae, are potentially pathogenic to humans and may be present in fish and raw or partially cooked shellfish ${ }^{3}$. The possibility of seafood consumers becoming infected with pathogenic Vibrio from oyster consumption depends on the microbiological quality of the marine habitat as well as the handling and processing practices of these shellfish ${ }^{4}$. The occurrence of these bacteria is not related to the counts of either Escherichia coli or thermotolerant coliforms, which are primarily responsible for gastroenteritis related to seafood consumption ${ }^{5}$.

Infections caused by Vibrio parahaemolyticus have been reported in $\mathrm{Asia}^{6-9}$, Europe (Spain ${ }^{10}$ and Italy $\left.{ }^{11}\right)$ and American countries (United States ${ }^{12-16}$, Chile ${ }^{17,18}$, Peru ${ }^{19}$ and Brazil ${ }^{20}$ ).

Pathogenic V.parahaemolyticus strains can be differentiated from non-pathogenic strains by their ability to produce thermostable hemolysin (TDH), which is known as the Kanagawa phenomenon. The pathogenicity of $V$. parahaemolyticus is associated with the presence of the $t d h$ and $t r h$ genes $^{21}$.

Infections caused by $V$. vulnificus show different clinical presentations, of which the primary septicemia, wound infections, and gastroenteritis are the most prevalent ${ }^{16}$. Vibrio vulnificus infections are serious and appear to be rare in Brazil, although there is little information concerning the actual incidence of these infections. 
The concentration of both $V$. parahaemolyticus and V. vulnificus in oysters is directly related to water temperature, with a higher concentration of this Vibrio present when the oysters are in warm water. Because of this, these microorganisms are rarely isolated when the water temperature is below $15^{\circ} \mathrm{C}^{22}$. In Brazil, the temperature of the seawater is greater than $20^{\circ} \mathrm{C}$ for the majority of the year, favoring the occurrence of these microorganisms in different stations.

This study aimed to identify and quantify the potentially pathogenic marine Vibrio in fresh oysters (Crassostrea gigas) and seawaters from different regions of bivalve shellfish cultivations in the South Bay of the Island of Santa Catarina, Brazil, as well as correlate the incidence of these microorganisms with the physicochemical parameters of the marine waters in these regions.

\section{METHODS}

\section{Collection and preparation of the samples}

Between October 2008 and March 2009, 60 oyster samples (Crassostrea gigas) and 60 seawater samples were collected from six regions of bivalve mollusk farms in the South Bay near the Island Santa Catarina $\left(27^{\circ} \mathrm{S}, 48^{\circ} \mathrm{W}\right)$, Brazil. These regions are identified as A, B, C, D, E and F in Figure 1. A total of 10 samplings were collected from each region.

Each oyster sample comprised 12 oysters, totaling 720 specimens. Water samples were collected following the methods published by the American Public Health Association ${ }^{23}$, which consisted of using sterile 1-liter polypropylene screw-cap containers $50 \mathrm{~cm}$ below the surface. The seawater temperature and dissolved oxygen levels were measured in situ using a YSI-550A dissolved oxygen meter (YSI Incorporated, Ohio, USA), salinity was measured using a refractometer (Alfakit, 211, Florianópolis, Brazil), and the Secchi depth was measured using a Secchi disc; all of these measurements were obtained in the field. However, the water $\mathrm{pH}$ was measured in a laboratory with a digital pH meter (Quimis ${ }^{\circledR}$ Q-400, São Paulo, Brazil). All measurements were obtained in triplicate. The oysters and water samples were transported to the laboratory in an isothermal box with packaged potable ice and analyzed within $3 \mathrm{~h}$ of sampling.

The oysters were scrubbed under tap water to remove debris, allowed to dry, disinfected with $70 \%$ ethanol, and opened aseptically using a sterilized knife. The flesh and intervalve liquid were aseptically transferred to sterile bags and homogenized for $1 \mathrm{~min}$, forming a pool of 12 oysters. The oysters' $\mathrm{pH}$ was evaluated from the pool of 12 oysters from each sample with a Quimis ${ }^{\circledR}$ Q-400 digital $\mathrm{pH}$ meter. This process was conducted in triplicate.

\section{Isolation and enumeration of Vibrio spp}

To detect the Vibrio spp. in oysters, $50 \mathrm{~g}$ of each sample was weighed, $450 \mathrm{~mL}$ of phosphate buffered saline (PBS, Oxoid, Ltd, England) was added to each sample and the mixtures were liquefied in a Bagmixer blender. Serial dilutions up to $10^{-4}$ were prepared from this homogenate, and $1 \mathrm{~mL}$ of each dilution was

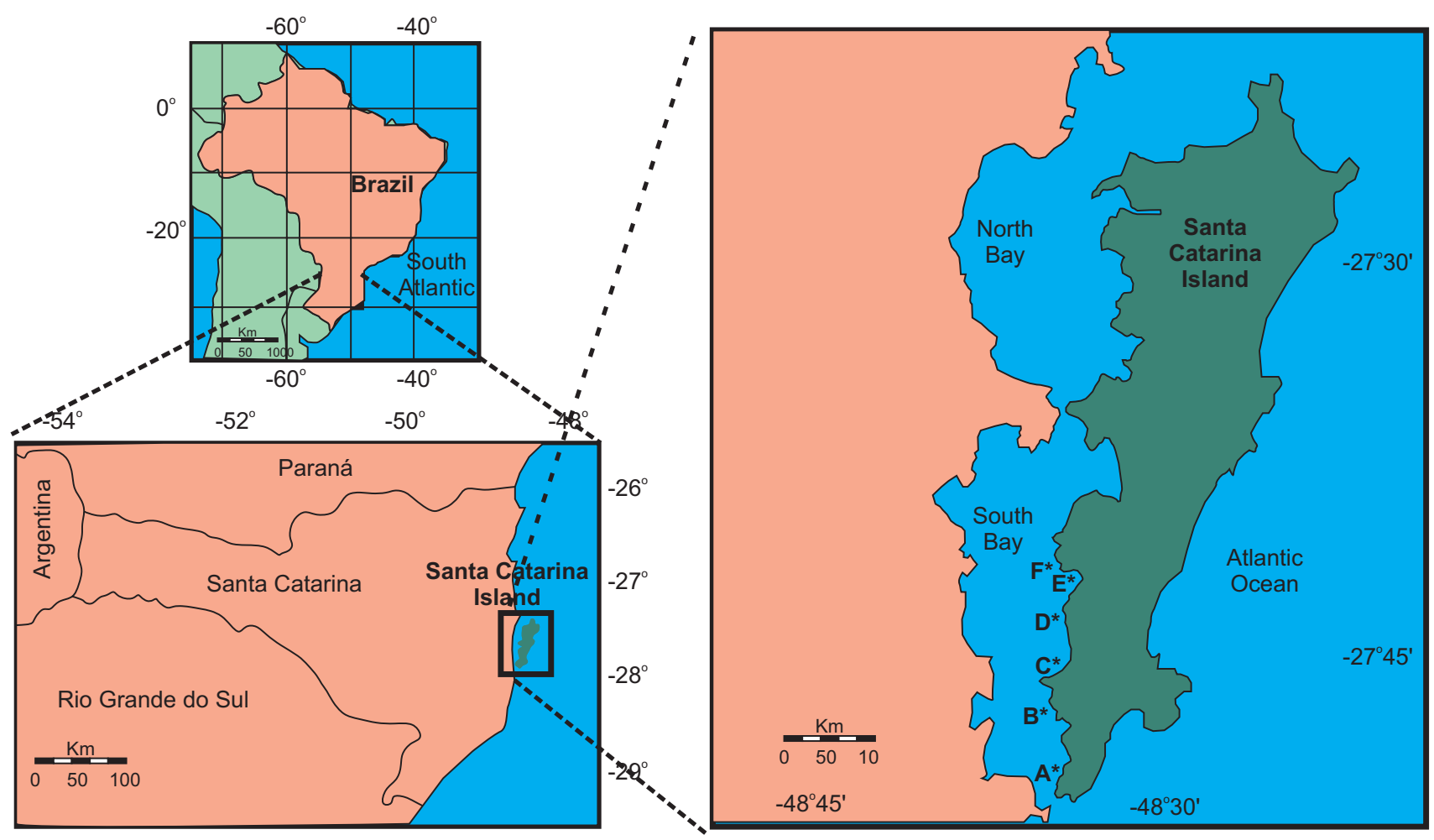

FIGURE 1 - Detailed map of the South Bay, with letters A through F indicating the sampling sites. 
inoculated into a tube containing alkaline peptone water (APW) and $3 \% \mathrm{NaCl}$ to enumerate the most probable number (MPN) of Vibrio parahaemolyticus and Vibrio vulnificus in the sample using a method described in the US Food and Drug Administration Bacterial Analytical Manual ${ }^{24}$. Each dilution was measured in triplicate. Further biochemical differentiation for the identification and confirmation of isolated particles were performed using the Analytical Profile Index (API) 20E system (bioMérieux, France).

For the water analysis, 5 tubes were prepared with alkaline peptone water (APW, Oxoid), concentrated twice with $3 \%$ of $\mathrm{NaCl}$, and two sets of 5 tubes were prepared with APW in normal concentration with $3 \% \mathrm{NaCl}$. Approximately $10 \mathrm{~mL}$ of collected water was added to the first set of 5 tubes, whereas 1 and $0.1 \mathrm{~mL}$ of cultivated water was added to the other two sets. The tubes were incubated at $35^{\circ} \mathrm{C}$ overnight, and those showing turbidity were sowed onto plates of Thiosulfate Citrate bile Sucrose agar (TCBS, Oxoid). These plates were incubated at $35^{\circ} \mathrm{C}\left( \pm 1^{\circ} \mathrm{C}\right)$ for 24 hours. The colonies that were suspected to be Vibrio spp. were inoculated into triple sugar iron agar (TSI, Oxoid) containing 3\% $\mathrm{NaCl}$ and subjected to indole motility sulfide agar (SIM, Oxoid) to determine motility, as well as an oxidase test (Newprov oxidase strips), gram coloration and inspection of bacterial morphology. Strains suspected in these tests were further subjected to taxonomic identification of the species using the API 20E kit from bioMérieux with a bacterial suspension containing $0.85 \% \mathrm{NaCl}$. The count result was obtained using the MPN table for the series of five tubes for each dilution $(10 \mathrm{~mL}, 1 \mathrm{~mL}$ and $0.1 \mathrm{~mL})$ according to section 9221C (APHA, 2005). All of the strains of $V$. parahaemolyticus were genotypically confirmed by detecting the th gene using multiplex polymerase chain reaction (multiplex-PCR).

\section{Determining pathogenicity}

Strains identified as $V$. parahaemolyticus were shipped in Luria Bertani agar containing 3\% $\mathrm{NaCl}$ to the Microbiology laboratory at the Institute Oswaldo Cruz (IOC) to determine pathogenicity. These strains were also subjected to the following phenotypical virulence tests: urease detection using Urea Agar Base (UAB, Oxoid) and hemolysis of human erythrocytes in Wagatsuma agar to detect the Kanagawa phenomenon ${ }^{24}$.

Genotypic confirmation of pathogenicity was performed using multiplex PCR detection of the $t d h$ (thermostable direct hemolysin) and trh (thermostable direct hemolysin-related hemolysin) genes using the following primers: VPTDH-L: 5'-gta aag gtc tct gac ttt tgg ac-3' and VPTDH-R: 5'-tgg aat aga acc ttc atc ttc acc-3'; VPTRH-L: 5'-ttg gct tcg ata ttt tca gta tct-3' and VPTRH-R: 5'-cat aac aaa cat atg ccc att tcc g-3', respectively. The $t$ th (thermolabile hemolysin) gene, which is a species-specific marker for $V$. parahaemolyticus, was amplified using the primers L-TL: 5'-aaa gcg gat tat gca gaa gca ctg-3' and R-TL: 5'-gct act ttc tag cat cat ttt ctc tgc-3', as described by Bacteriological Analytical Manual/Food and Drug Administration (BAM/FDA $)^{24}$.

\section{Statistical analysis}

Results of the microbiological tests were transformed into log values and assumed to be normally distributed; statistical analyses were performed using Statistica $7.0^{\circledR}$ software (Stat-Soft, Inc., USA). To facilitate the statistical analyses of quantitative data obtained by the most probable number, counts for $V$. parahaemolyticus and V. vulnificus when the levels were below the limit of detection were substituted for $2 \mathrm{MPN} \mathrm{g}^{-1}$ oyster and $1.7 \mathrm{MPN} \cdot 100 \mathrm{~mL}^{-1}$ seawater. A test of significance of the observed differences in V. parahaemolyticus and $V$. vulnificus levels regarding the environmental parameters in oysters and seawater across the six sites sampled was conducted using oneway analysis of variance (ANOVA). An alpha level of 0.05 was considered to be the minimum level for statistical significance.

The influence of the physicochemical microbiological counts in seawater was evaluated by analyzing the nonparametric Spearman rank correlation, whereas the correlation between the physical and chemical parameters and incidence of Vibrio spp. was assessed by the Pearson correlation.

\section{RESULTS}

Collections were performed from October 2008 to March 2009, which included the spring and summer seasons, and the temperature of the seawater ranged from $20^{\circ} \mathrm{C}$ and $29^{\circ} \mathrm{C}$. The average temperature of the six geographically studied regions was $24.3^{\circ} \mathrm{C} \pm 2.2$.

Of the 60 examined oyster samples, $29(48.3 \%)$ were found to contain potentially pathogenic Vibrio spp. (Table 1). The most frequently isolated species from the oysters were V. parahaemolyticus (21 isolates, $35 \%$ ), V. vulnificus (6 isolates, $10 \%$ ) and $V$. alginolyticus (4 isolates, 6.7\%). V. cholerae was not isolated from any of the 60 analyzed samples, and $V$.fluvialis was isolated from only one sample. The $V$. parahaemolyticus counts ranged from $<0.5 \log _{10}$ MPN g-1 oyster (non-detectable) to 2.3 $\log _{10} \mathrm{MPN} \mathrm{g}^{-1}$ oyster, with the mean level of $V$. parahaemolyticus in the oyster samples at $1.2 \log _{10} \mathrm{MPN} \cdot \mathrm{g}^{-1}$ oyster. The V. vulnificus counts ranged from $<0.5 \log _{10} \mathrm{MPN} \cdot \mathrm{g}^{-1}$ oyster (non-detectable) to $2.1 \log _{10} \mathrm{MPN} \cdot \mathrm{g}^{-1}$ oyster, and the mean level of $V$. vulnificus was $0.8 \log _{10} \mathrm{MPN} \mathrm{g}^{-1}$ oyster. In December and January, which is summertime in Brazil, the highest counts of $V$. vulnificus and $V$. parahaemolyticus were observed in the oyster samples. Interestingly, two Vibrio species coexisted in three oyster samples (Table 1).

During the entire monitoring period, 32 Vibrio strains were isolated from the oyster samples. In the $\mathrm{C}$ region, the incidence of Vibrio was higher compared to the other regions.

Based on ANOVA (Table 2), there were no significant differences in the mean $\log _{10}$ density of total counts of Vibrio parahaemolyticus and $V$. vulnificus in the oyster samples from the six sites tested $(\mathrm{p}>0.05)$.

Of the 60 seawater samples collected, $44(73.3 \%)$ had one or more Vibrio species. The most frequently isolated species from the seawater were $V$. parahaemolyticus (27 isolates, $45 \%$ ), V. alginolyticus (17 isolates, $28.3 \%$ ) and $V$. vulnificus (8 isolates, $13.3 \%)$. V. cholerae, the only Vibrio species surveyed that originates from waters contaminated by sewage, was not isolated in any of the 60 samples analyzed, and V. fuvialis was found in only one sample. 
TABLE 1 - Prevalence of Vibrio in oysters and seawater.

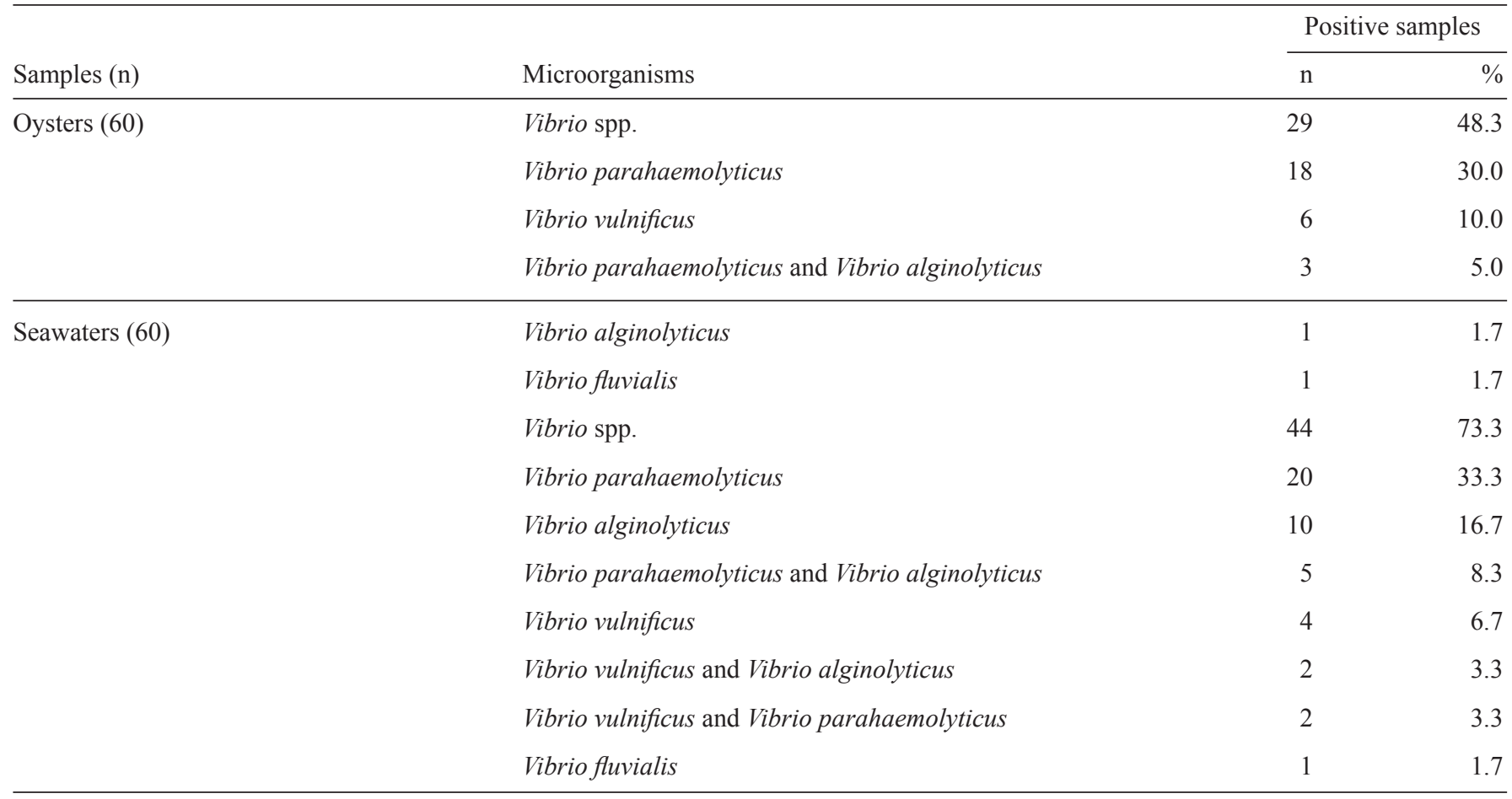

TABLE 2 - Results of microbiological analysis and seawater parameters of samples collected from the South Bay of Santa Catarina, Brazil.

\begin{tabular}{|c|c|c|c|c|c|c|}
\hline \multirow[b]{2}{*}{ Site } & \multicolumn{2}{|c|}{ Seawater parameters } & \multirow{2}{*}{$\begin{array}{c}V P \text { in oysters log } \\
\mathrm{MPN} \cdot \mathrm{g}^{-1} \\
\text { mean } \pm \mathrm{SD}^{*}\end{array}$} & \multirow{2}{*}{$\begin{array}{c}V P \text { in seawater log } \\
\mathrm{MPN} \cdot 100 \mathrm{~mL}^{-1} \\
\text { mean } \pm \mathrm{SD}^{*}\end{array}$} & \multirow{2}{*}{$\begin{array}{c}V V \text { in oyster log } \\
\text { MPN } \cdot \mathrm{g}^{-1} \\
\text { mean } \pm \mathrm{SD}^{*}\end{array}$} & \multirow{2}{*}{$\begin{array}{c}V P \text { in seawater log } \\
\mathrm{MPN} \cdot 100 \mathrm{~mL}^{-1} \\
\text { mean } \pm \mathrm{SD}^{*}\end{array}$} \\
\hline & $\mathrm{T}\left({ }^{\circ} \mathrm{C}\right)$ & $\mathrm{S}(\mathrm{ppm})$ & & & & \\
\hline B & $23.3 \pm 1.9^{\mathrm{ab}}$ & $33.3 \pm 3.3^{\mathrm{a}}$ & $0.8 \pm 0.7^{\mathrm{a}}$ & $0.4 \pm 0.3^{\mathrm{a}}$ & $0.4 \pm 0.2^{\mathrm{a}}$ & $0.3 \pm 0.2^{\mathrm{a}}$ \\
\hline $\mathrm{C}$ & $24.6 \pm 2.0^{\mathrm{ab}}$ & $32.8 \pm 3.5^{\mathrm{a}}$ & $0.9 \pm 0.6^{\mathrm{a}}$ & $0.6 \pm 0.5^{\mathrm{a}}$ & $0.3 \pm 0.0^{\mathrm{a}}$ & $0.3 \pm 0.2^{\mathrm{a}}$ \\
\hline $\mathrm{E}$ & $24.9 \pm 2.0^{\mathrm{ab}}$ & $30.7 \pm 6.5^{\mathrm{a}}$ & $0.7 \pm 0.7^{\mathrm{a}}$ & $0.8 \pm 0.4^{\mathrm{a}}$ & $0.3 \pm 0.0^{\mathrm{a}}$ & $0.2 \pm 0.0^{\mathrm{a}}$ \\
\hline $\mathrm{F}$ & $25.2 \pm 2.3^{\mathrm{b}}$ & $31.2 \pm 4.0^{\mathrm{a}}$ & $0.8 \pm 0.0^{\mathrm{a}}$ & $0.5 \pm 0.5^{\mathrm{a}}$ & $0.7 \pm 0.6^{\mathrm{a}}$ & $0.4 \pm 0.4^{\mathrm{a}}$ \\
\hline
\end{tabular}

T: temperature; S (ppm): salinity parts-per-million; VP: Vibrio parahaemolyticus; VV: Vibrio vulnificus; MPN: most probable number; SD: standard deviation. * means $(\mathrm{n}=3)$ in the column with different superscripts $(\mathrm{a}, \mathrm{b})$ are significantly different $(\mathrm{p}<0.05)$.

The Vibrio parahaemolyticus counts ranged from $<0.3$ $\log _{10} \mathrm{MPN} \cdot 100 \mathrm{~mL}^{-1}$ seawater (non-detectable) to $1.7 \log _{10}$ MPN $\cdot 100 \mathrm{~mL}^{-1}$ seawater, and the mean level of $V$. parahaemolyticus in the seawater samples was $0.8 \log _{10} \mathrm{MPN} \cdot 100 \mathrm{~mL}^{-1}$, whereas the $V$. vulnificus counts ranged from $<0.3 \log _{10}$ MPN $100 \mathrm{~mL}^{-1}$ seawater (non-detectable) to $2.0 \log _{10} \mathrm{MPN} \cdot 100 \mathrm{~mL}^{-1}$ seawater, and the mean level of $V$. vulnificus was $0.6 \log _{10}$ MPN $100 \mathrm{~mL}^{-1}$ seawater. Two Vibrio species coexisted in nine seawater samples (Table 1).

Spearman correlation analysis indicated a significant positive correlation between the $\log _{10}$ total of $V$. vulnificus counts in the seawater and oysters at the same site of the South Bay $(\mathrm{p}<0.05)$; however, the same was not observed for V. parahaemolyticus $(\mathrm{p}>0.05)$.

The influence of temperature on the concentration of Vibrio in the marine waters was only observed with $V$. vulnificus $(\mathrm{p}<0.05)$. For $V$. parahaemolyticus $(\mathrm{p}>0.05)$, no Spearman correlation was established, presumably due to samplings that were conducted during the spring and summer months when water temperatures remained at approximately $24^{\circ} \mathrm{C}$ on average, resulting in the continuous detection of different species of Vibrio. 
A negative Spearman correlation was observed between the counts of $V$. parahaemolyticus and salinity $(\mathrm{p}<0.05)$; however, this was not observed with $V$. vulnificus $(\mathrm{p}>0.05)$. The seawater clarity, dissolved oxygen and $\mathrm{pH}$ measurements were not correlated with the level of contamination with either $V$. parahaemolyticus $(\mathrm{p}>0.05)$ or $V$. vulnificus $(\mathrm{p}>0.05)$. The incidence of different species of marine vibrio in the water did not correlate with any of the physicochemical parameters measured $(\mathrm{p}>0.05)$. The $\mathrm{pH}$ values of the oysters from the different regions of the South Bay ranged between 5.8 and 6.8, and the average $\mathrm{pH}$ observed was $6.2 \pm 0.2$. Although Brazilian laws have set $\mathrm{pH}$ limits for fish, there are none for mollusks.

Only one of the 48 strains isolated from oyster and seawater samples (confirmed to be V. parahaemolyticus by th detection) was urease-positive, but the strain did not produce b-hemolysis halos in Wagatsuma agar. The $t d h$ gene was detected in four strains, and trh was detected in 23 strains (Figure 2).
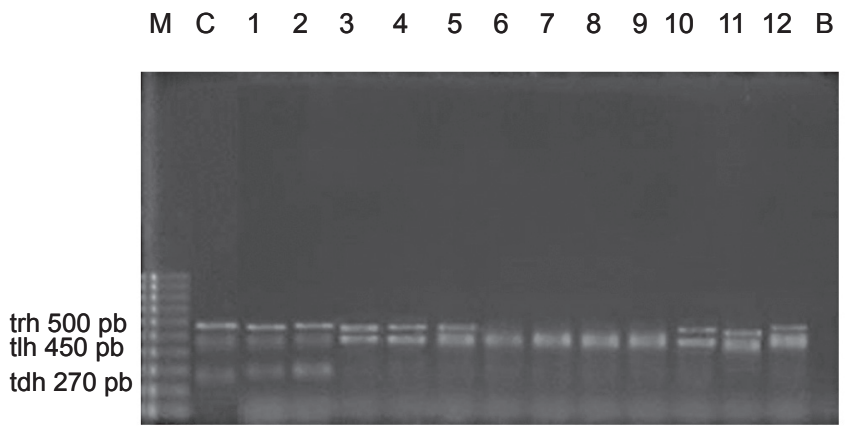

FIGURE 2 - Agarose gel electrophoresis of the multiplex PCR products obtained from the collected Vibrio parahaemolyticus strains. Lanes: M: 100bp molecular weight marker; C: positive control (tlh-, trh-and $t d h$-positive $V$.parahaemolyticus); B: negative control; 1 and 2 , positive for $t r h$ and $t d h ; 3,4,5,10,11$ and 12 , positive for $t r h ; 1-12$, positive for $t h$.

\section{DISCusSION}

Similar mean water temperatures were observed at the six sites investigated except the temperatures of regions $\mathrm{A}$ and $\mathrm{F}$, where a significant difference was observed $(\mathrm{p}<0.05)$. This most likely occurred because the collections took place early in the morning in the A region and approximately $12 \mathrm{~h}$ later in the F region, over which time the water temperature experiences a natural increase.

The average temperature of $24.3^{\circ} \mathrm{C}$ in the water of the six sampling stations in South Bay of Santa Catarina Island was favorable for the development of Vibrio because pathogenic Vibrio are more frequently isolated in an aquatic environment with temperatures varying between 10 and $30^{\circ} \mathrm{C}^{25}$. According to Strom and Paranjpye ${ }^{26}, V$. vulnificus proliferates in areas when the water temperature exceeds $18^{\circ} \mathrm{C}$. The lowest recorded temperature of all of the samples was $20^{\circ} \mathrm{C}$.
Several studies have suggested a strong influence of temperature on the concentration of vibrio in marine waters ${ }^{27-30}$. However, this study only established a correlation with $V$. vulnificus $(\mathrm{p}<0.05)$. For $V$. parahaemolyticus $(\mathrm{p}>0.05)$, it was not possible to establish any correlation, presumably due to the average water temperature of $24^{\circ} \mathrm{C}$, which enabled the continuous detection of different species of Vibrio.

In this study, the prevalence and concentration of V. parahaemolyticus were lower compared to studies performed in southeastern regions of Brazil ${ }^{31-33}$. Although no isolated Kanagawa-positive strains have been isolated, $6.7 \%$ of the strains isolated in this study contained $t d h$ and $38.3 \%$ of the strains contained trh, both of which are related to the pathogenicity of $V$. parahaemolyticus.

Kanagawa-negative strains carrying the $t d h$ gene produce TDH and are therefore potentially toxigenic. The only ureasepositive strain, which also contained the trh gene, has been previously described by other authors ${ }^{4,34}$. According to these studies, urease positivity is an indication of virulence.

In this study, more than half of the isolates were V. parahaemolyticus; this percentage of isolates is different from that previously observed in another study conducted in the same region $^{35}$. The variability in the incidence of different species of Vibrio may be related to the fact that this study was conducted in the warmer spring and summer seasons, whereas the other study covered all four seasons. Vieira et al. ${ }^{4}$ also observed a higher prevalence of $V$. parahaemolyticus (30.3\% of those isolated) in the oyster samples.

In Brazil, the bacteriological quality of the aquaculture water areas is evaluated by either fecal coliforms or the Escherichia coli tes ${ }^{36}$. Through Resolution 12/2001, the Department of Sanitary Vigilance ${ }^{37}$ determined the maximum acceptable level of $V$. parahaemolyticus in raw seafood-based dishes to be $10^{3}$ per gram. Though oysters are not mentioned explicitly in this definition, they should be considered as raw seafood because they are traditionally consumed in nature. Considering this legislation as a parameter put the results observed in our study into context, the $V$. parahaemolyticus counts reported here vary below the maximum-allowed limit.

The United States, through the Guide for the Control of Molluscan Shellfish, which was published by the National Shellfish Sanitation Program ${ }^{38}$, has established action levels and levels of concern for $V$. parahaemolyticus levels that are equal to or greater than an MPN count of 10,000 per gram, as well as Kanagawa positive or negative strains. However, the recommended attention to $V$. vulnificus does not establish limits for this microorganism, which must be analyzed on a case-by-case basis.

Many factors are involved in the distribution and survival of microorganisms in estuarine ecosystems, such as biotic and abiotic parameters of the surrounding seawater (i.e., temperature, salinity, $\mathrm{pH}$ and turbidity $)^{30,32,39}$. The concentration of $V$. parahaemolyticus in seawater increases with rising water temperatures and corresponds to a seasonal increase, with sporadic cases reported in the warmer months ${ }^{40}$. According to the Centers for Disease Control (CDC) ${ }^{13}$, outbreaks of 
V. parahaemolyticus infections in the Pacific Northwest and Texas occur primarily during the summer months. However, this study showed no correlation between the $V$. parahaemolyticus counts and the water temperature, most likely due to the minimal temperature variation over the study period, whereas a significant correlation was observed between the $V$. vulnificus counts and water temperature, confirming the previously reported results ${ }^{41,42}$.

Audemard et al. ${ }^{43}$ suggested that unexplored postharvest processing (PHP) methods to eliminate $V$. vulnificus from oysters, which use relaying to high salinity waters, could be an alternative strategy, considering that high salinities appear to negatively affect the survival of $V$. vulnificus. However, this study observed a negative correlation between salinity and $V$.parahaemolyticus, whereas no correlation was observed between salinity and V. vulnificus; this result is consistent with results obtained in other studies conducted in shellfish cultivation areas off the Brazilian coast $^{32,35}$ and in other parts of the world ${ }^{41,44}$.

Although the V. parahaemolyticus and V. vulnificus counts observed in the waters can be considered as low, it is important to note that in filtering shellfish such as oysters and mussels, these microorganisms are concentrated in their guts and in other tissues, with levels reaching up to $10^{6}$ bacteria per gram of shellfish ${ }^{30}$.

Although only eight (13.3\%) samples in this study were positive for $V$. vulnificus (even at low concentrations), these data should serve as an indication for the need for constant monitoring of this species in areas of bivalve shellfish cultivation due to the ability of this organism to cause serious infections that are often fatal ${ }^{30}$.

The results of this study suggest the need to improve strategies to prevent the occurrence of diseases transmitted by consumption of bivalve shellfish contaminated with pathogenic vibrio. This translates to monitoring not only indicators of fecal contamination, such as Escherichia coli, but also the potentially pathogenic Vibrio. Additionally, establishing time and temperature parameters for the handling, transporting, marketing, distribution and consumption of these shellfish is imperative to prevent illnesses due to these foodborne pathogens.

\section{CONFLICT OF INTEREST}

The authors declare that there is no conflict of interest.

\section{FINANCIAL SUPPORT}

This study was supported by the Conselho Nacional de Desenvolvimento Científico e Tecnológico (CNPq) and Fundação de Amparo à Pesquisa do Estado de Santa Catarina (FAPESC).

\section{REFERENCES}

1. Coelho C, Heinert AP, Simões CM, Barardi CR. A virus detection in oysters (Crassostrea gigas) in Santa Catarina State, Brazil, by reverse transcription-polymerase chain reaction. J Food Protc 2003; 66:507-511.

2. Corrêa AA, Albarnaz JD, Moresco V, Poli CR, Teixeira AL, Simões CM. Depuration dynamics of oysters (Crassostrea gigas) artificially contaminated by Salmonella enterica serovar Typhimurium. Mar Environ Res 2007; 63:479-489.

3. Thompson FL, Iida T, Swings J. Biodiversity of Vibrio. Microbiol Mol Biol Rev 2004; 68:403-431.

4. Vieira RHSF, Costa RA, Menezes FGR, Silva GC. Kanagawa-Negative, tdh- and trh-Positive Vibrio parahaemolyticus Isolated from Fresh Oysters Marketed in Fortaleza, Brazil Curr Microbiol 2011; 63:126-130.

5. Martinez-Manzares E, Mornigo MA, Castro D, Babelona MC, Munoz MA, Borrego JJ. Relationship between indicators of faecal pollution in shellfishgrowing water and occurrence of human pathogenic microorganisms in shellfish. J Food Protc 1992;55:609-614.

6. Pan TM, Wang TK, Lee CL, Chien SW, Horng CB. Food-borne disease outbreaks due to bacteria in Taiwan, 1986 to 1995. J Clin Microbiol 1997; 35:1260-1262.

7. Lee WC, Lee MJ, Kim JS, Park SY. Foodborne illness outbreaks in Korea and Japan studied retrospectively. J Food Prot 2001; 64:899-902.

8. Su HP, Chiu SI, Tsai JL, Lee CL, Pan TM. Bacterial food-borne illness outbreaks in northern Taiwan, 1995 e 2001. J Infect Chemother 2005; 11:146-151

9. Kubota K, Iwasaki E, Inagaki S, Nokubo T, Sakurai Y, Komatsu M, et al. The Human Health Burden of Foodborne Infections Caused by Campylobacter, Salmonella, and Vibrio parahaemolyticus in Miyagi Prefecture, Japan. Foodborne Pathog Dis 2008; 5: 641-648.

10. Lozano-Leon A, Torres J, Osorio CR, Martinez-Urtaza J. Identification of tdh-positive Vibrio parahaemolyticus from an outbreak associated with raw oyster consumption in Spain. FEMS Microbiol Lett 2003; 226:281-284.

11. Ottaviani D, Leoni F, Rocchegiani E, Santarelli S, Canonico C, Masini L, et al. First clinical report of pandemic Vibrio parahaemolyticus O3:K6 infection in Italy. J Clin Microbiol 2008; 46:2144-2145.

12. Centers for Disease Control (CDC) Outbreak of Vibrio parahaemolyticus infections associated with eating raw oysters - Pacific Northwest, 1997. Morb Mortal Wkly Rep 1998; 47:457-462.

13. Centers for Disease Control (CDC). Outbreak of Vibrio parahaemolyticus infection associated with eating raw oysters and clams harvested from Long Island Sound-Connecticut, New Jersey, and New York. Morb Mortal Wkly Rep 1999; 48:48-51.

14. McLaughlin JB, DePaola A, Bopp CA, Martinek KA, Napolilli NP, Allison CG, et al. Outbreak of Vibrio parahaemolyticus gastroenteritis associated with Alaskan oysters. New Engl J Med 2005; 351:1463-1470.

15. Centers for Disease Control (CDC). Vibrio parahaemolyticus infections associated with consumption of raw shellfish - three states, 2006. Morb Mortal Wkly Rep 2006; 55:854-856.

16. Drake SL, DePaola A, Jaykus LA. An overview of Vibrio vulnificus and Vibrio parahaemolyticus. Compr Rev Food Sci Food Saf 2007; 6:120-144.

17. Harth E, Matsuda L, Hernández C, Rioseco ML, Romero J, GonzalezEscalona N, et al. Epidemiology of Vibrio parahaemolyticus outbreaks, southern Chile. Emerg Infect Dis 2009; 15:163-168.

18. Gil AI, Miranda H, Lanata CF, Prada A, Hall ER, Barreno CM, et al. O3:K6 Serotype of Vibrio parahaemolyticus identical to the global pandemic clone associated with diarrhea in Peru. Int J Infect Dis 2007; 11:324-328.

19. Martinez-Urtaza J, Simental L, Velasco D, DePaola A, Ishibashi M, Nakaguchi Y, et al. Pandemic Vibrio parahaemolyticus O3:K6, Europe. Emerg Infect Dis 2005; 11:1319-1320.

20. Leal NC, da Silva SC, CavalcantiVO, Figueiroa ÂCT, NunesVV, Miralles IS, et al. Vibrio parahaemolyticus serovar $\mathrm{O} 3: \mathrm{K} 6$ gastroenteritis in northeast Brazil. J Appl Microbiol 2008; 105:691-697.

21. Nishibuchi M, Kaper JB. Thermostable direct hemolysin gene of Vibrio parahaemolyticus: a virulence gene acquired by a marine bacterium. Infect Immun 1995; 63:2093-2099.

22. Su Y, Liu C. Vibrio parahaemolyticus: A concern of seafood safety. Food Microbial 2007; 24:549-558.

23. American Public Health Association APHA, American Water Works Association AWWA, Water Environment Federation - WEF. Standard 
Methods for the Examination of Water and Wastewater. $21^{\text {st }}$ edition. Washington DC, USA; 2005. p 1336.

24. Kaysner CA, DePaola Jr A. Vibrio cholerae, V. parahaemolyticus, V. vulnificus, and other Vibrio spp. In US Food and Drug Adminstration/ Center for Food Safety \& Applied Nutrition (US FDA/CFSAN). Bacteriological Analytical Manual Online 2001, Chapter 9, revisad May 2004. http:// www.cfsan.fda.gov Accessed 10 July 2008.

25. Matté GR, Matte MH, Sato MIZ, Sanchez PS, Rivera IG, Martins MT. Potentially pathogenic vibrios associated with mussels from a tropical region on the Atlantic Coast of Brazil. J Appl Bact 1994; 77:201-207.

26. Strom MS, Paranjpye RN. Epidemiology and pathogenesis of Vibrio vulnificus. Microb Infect 2000; 2:177-188.

27. Chae MJ, Cheney D, Su YC. Temperature Effects on the Depuration of Vibrio parahaemolyticus and Vibrio vulnificus from the American Oyster (Crassostrea virginica). J Food Sci 2009; 74:62-66.

28. Deepanjali A, Kumar H, Karunasagar I. Seasonal variation in abundance of total and pathogenic Vibrio parahaemolyticus bacteria in oysters along the southwest coast of India. Appl Environ Microbiol 2005; 71: 3575-3580

29. Depaola A, Nordstrom JL, Bowers JC, Wells JG, Cook DW. Seasonal abundance of total and pathogenic Vibrio parahaemolyticus in Alabama oysters. Appl Environ Microbiol 2003; 56:2299-2302.

30. Wang D, Zhang D, Chen W, Yu S, Shi X. Retention of Vibrio parahaemolyticus in oyster tissues after chlorine dioxide treatment. Int J Food Microbiol 2010; 137:76-80.

31. Costa Sobrinho OS, Destro MT, Franco BDGM, Landgraf M. Correlation between environmental factors and prevalence of Vibrio parahaemolyticus in oysters harvested in the southern coastal area of São Paulo state, Brazil. Appl Envir Microbiol 2010; 76:1290-1293.

32. Ristori CA, Iaria ST, Gelli DS, Rivera ING. Pathogenic bacteria associated with oysters (Crassostrea brasiliana) and estuarine water along the south coast of Brazil. Int J Environ Health Res 2007; 17:259-269.

33. Costa Sobrinho OS, Destro MT, Franco BDGM, Landgraf M. Occurrence and distribution of Vibrio parahaemolyticus in retail oysters in Sao Paulo State, Brazil. Food Microbiol 2011; 28:137-140.
34. Suthienkul O, Ishibashi M, Iida T, Nettip N, Supavej S, Eampokalap B. Urease production correlates with possession of the trh gene in Vibrio parahaemolyticus strains isolated in Thailand. J Infect Dis 1995; 172:1405-1408.

35. Ramos RJ, Pereira MA, Miotto LA, Faria RD, Silveira Jr N, Vieira CRW. Ocurrence of Vibrio spp., positive coagulase staphylococci and enteric bacteria in oysters (Crassostrea gigas) harvested in the south bay of Santa Catarina Island, Brazil. Ciênc Tecnol Aliment 2012; 32:478-484.

36. Conselho Nacional do Meio Ambiente. Brasil. Resolução 357 de 17 de março de 2005. Diário Oficial. Brasília 18 março de 2005.

37. Resolução RDC $n^{\circ} 12$ de 02 de janeiro de 2001. Brasil. Aprova o regulamento técnico princípios gerais para estabelecimento de critérios e padrões microbiológicos para alimentos e seus anexos I, II e III. Diário Oficial. Brasília, 1 de janeiro de 2001.

38. United States, Food and Drug Administration (USFDA) National Shellfish Sanitation Program model ordinance 2009. http://www.fda.gov/Food/ FoodSafety/ProductSpecificInformation/Seafood/FederalStatePrograms/ NationalShellfishSanitationProgram. Accessed 05 June2010.

39. Rippey SR. Infectious diseases associated with molluscan shellfish consumption. Clin Microbiol Rev 1994; 7:419-425.

40. Hlady WG, Klontz KC. The epidemiology of Vibrio infections in Florida, 1981-1993. J Infect Dis 1996; 173:1176-1183.

41. Høi L, Larsen JL, Dalsgaard I, Dalsgaard A. Occurrence of Vibrio vulnificus Biotypes in Danish Marine Environments. Appl Environ Microbiol 1998; 64:7-13.

42. Lhafi SK, Kühne M. Occurence of Vibrio spp. in blue mussels (Mytilus edulis) from the German Wadden Sea. Int J Food Microbiol 2007; 116:297-300.

43. Audemard C, Kator HI, Rhodes MW, Gallivan T, Erskine AJ, Leggett AT, et al. High salinity relay as a postharvest processing strategy to reduce Vibrio vulnificus levels in Chesapeake Bay oysters (Crassostrea virginica). J Food Prot 2011; 74:1902-1907.

44. Parveen S, Hettiarachchi KA, Bowers JC, Jones JL, Tamplin ML, McKay R, et al. Seasonal distribution of total and pathogenic Vibrio parahaemolyticus in Chesapeake Bay oysters and waters. Int J Food Microbiol 2008; 128:354-361. 